\title{
Characterization of Al/MWCNTs composites prepared by powder metallurgy routes
}

\author{
F. Housaer ${ }^{1}$, A. Legris ${ }^{1}$, F. Béclin ${ }^{1}$, M. Touzin ${ }^{1}$, D. Tingaud ${ }^{2}$, G. Ji ${ }^{1}$ and R. Shabadi ${ }^{1}$ \\ ${ }^{1}$ Unité Matériaux et Transformations, UMR CNRS 8207, Université Lille1, 59655 Villeneuve d'Ascq, France \\ 2 Laboratoire des Sciences des procédés et des Matériaux, Université Paris 13, Institut Galilée, 99 Av. J.B. \\ Clément, 93430 Villetaneuse, France
}

\begin{abstract}
Aluminum (Al) matrix composite reinforced with $0.5 \%$ in weight of multi-walled carbon nanotubes (MWCNTs) are synthetized by powder metallurgy. Spark plasma sintering (SPS) or hot pressing (HP) are used to obtain fully dense materials. Moreover, particular attention is given to the powder preparation in order to uniformly disperse the nanotubes within the metal matrix. To that end, successive mechanical and chemical treatments are applied to MWCNTs. These treatments are described here. The dispersion improvement is assessed by composite micro-hardness measurements which reveal an increase of about $25 \%$ compared to pure Al. Furthermore the microstructure study highlights the formation of a complex phase at grain boundaries. The CNT dispersion process optimization combined to the mechanical properties and microstructure investigations should allow a better understanding of the reinforcement mechanisms in this composite.
\end{abstract}

\section{INTRODUCTION}

The current rise in oil prices forces manufacturers to find ways to reduce the consumption of vehicles. The weight decrease is one of the solutions but requires the development of new materials. The unalloyed aluminum is known for its low density $\left(2.6989 \mathrm{~g} / \mathrm{cm}^{3}\right)$ and its resistance to corrosion, but it suffers from its lack of rigidity preventing its use as a structural material. Thus, the use of aluminum matrix composites (AMC) with improved properties by adding reinforcements could overcome this weakness. Indeed the association of the lightness of aluminum and the remarkable mechanical properties of multi-walled carbon nanotubes (MWCNTs) should lead to the conception of a very promising material for many applications such as aeronautic. The composite mechanical properties strongly depend on their microstructure that should remain fine and homogenous but also on the good dispersion of carbon nanotube at grain boundaries. Thus, this new materials is developed using powder metallurgy routes with a particular attention given to the powder preparation. The composite preparation process is developed in order to improve the nanotubes dispersion. The reinforcement mechanisms in the Al/MWCNTs composites are studied thanks to microstructure observations and mechanical tests.

\section{EXPERIMENTAL}

\section{Al/MWCNTs composite powder preparation}

The commercial Aluminum powder (99\% purity, average particle size of $15 \mu \mathrm{m}$ ) and MWCNTs (90\% of purity, with a diameter of $9.5 \mathrm{~nm}$ and a length of 1.5 microns) used in this study are shown in Figure 1.

Figure 2 illustrates the composite powder preparation process. It consists in modifying the nanotubes surface to prevent their agglomeration due to their very low dimension. Thus MWCNTs undergo successively a mechanical dispersion (MCNTs-d), an oxidation with diluted nitric acid (MWCNTs-HNO3) and finally a surface treatment with sodium dodecyl sulfate (SDS) surfactant (SDS-MWNTs) [2,3]. After each step, the required amount of nanotubes was withdrawn and incorporated in the aluminum powder by co-milling. Then the mixture is consolidated and studied. Figure 3 shows the powder $\mathrm{Al} / \mathrm{MWCNTs}-0.5 \mathrm{wt} . \%$ after oxidation. $\mathrm{Al}$ particles, flattened during ball milling have flake shapes (white arrow). The presence of MWCNTs clusters (white circle) is also highlighted. This aspect will be studied in this work.

\section{Composite consolidation}

The Al-MWCNTs mixture (powder) was first debonded at $400{ }^{\circ} \mathrm{C}$ under argon atmosphere and then consolidated in a carbon mold by Spark Plasma Sintering (SPS) or hot pressing. In both cases, the applied pressure is $80 \mathrm{MPa}$ and the sintering temperature is $580^{\circ} \mathrm{C}$.

\section{Characterization}

The composites density was measured by Archimedes's principle. The composites microstructure was examined using transmission electron microscopy (TEM) and field emission scanning electron microscopy (FESEM). The micro-hardness test was carried out in a micro-hardness tester using Vickers indenter under load control.

\section{RESULTS}

\section{Microstruture}

FESEM observations reveal that all consolidated composite materials have a similar microstructure. Grains 

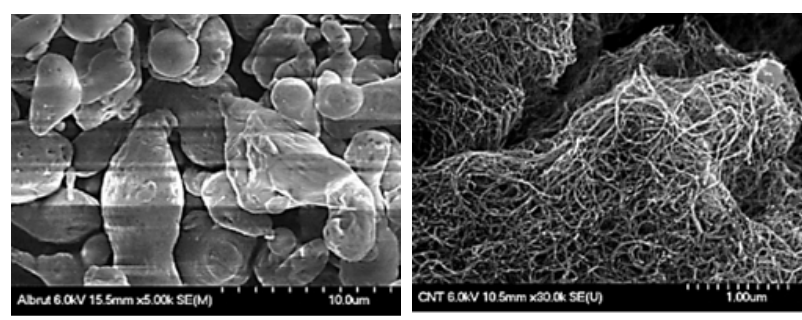

Figure 1. FESEM images of raw Al powder and MWCNTs.

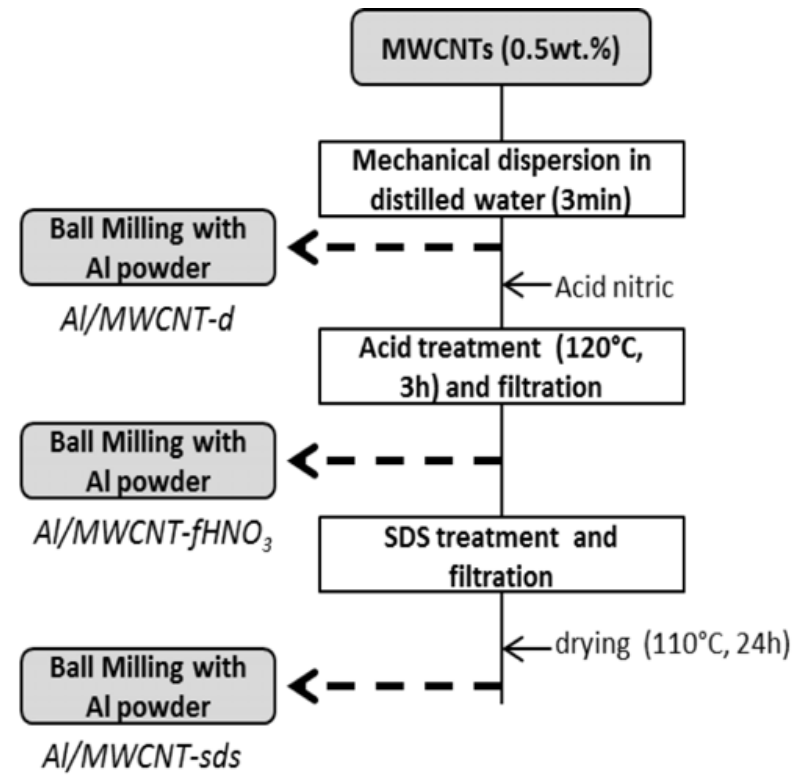

Figure 2. Composite powder preparation process.

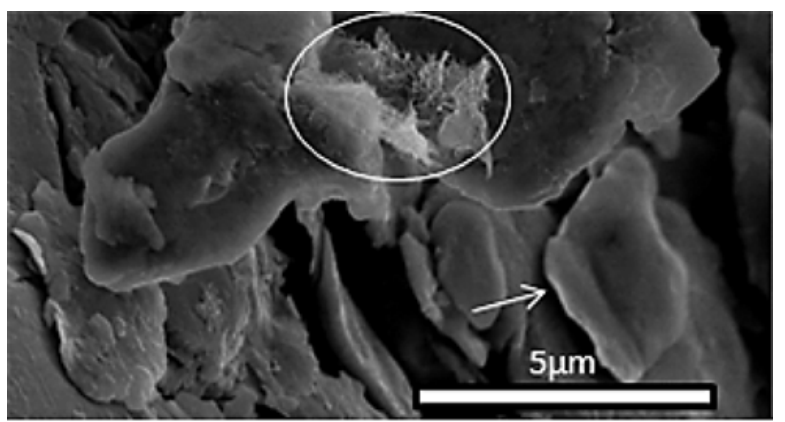

Figure 3. FESEM image of Al/MWCNTs $0.5 w t$. \% powder after oxidation.

are aligned perpendicularly to the compression axis. Moreover, a complex phase can be observed at grain boundaries (as shown in Fig. 4).

TEM investigations also highlight a complex phase at grain boundaries where some CNTs basal plans can be observed, revealing the multi-walled structure (as shown in Fig. 4 by the black arrows). Micrograph on the left presents the untreated Al/MWCNT-d powder just after ball milling and on the right the chemically treated and sintered Al/MWCNT-sds sample. After chemical dispersion and consolidation, CNTs are still present, but the number of walls seems to have decreased.

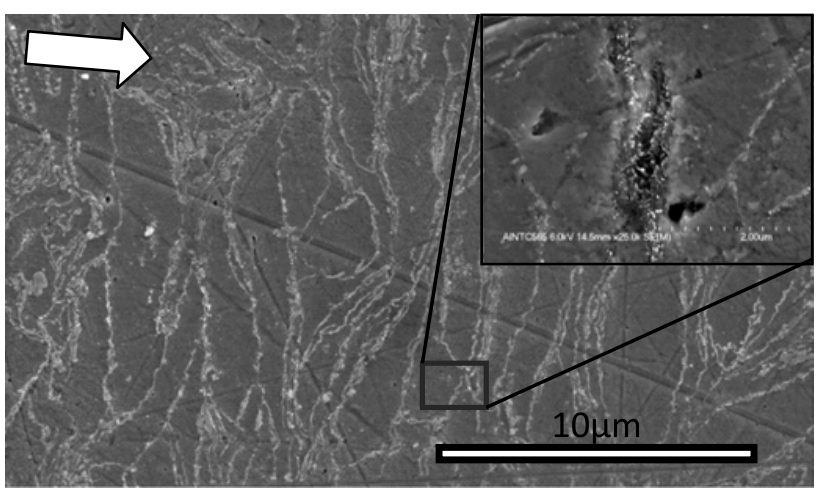

Figure 4. FESEM image of Al-MWCNTs0.5wt.\% after oxidation.

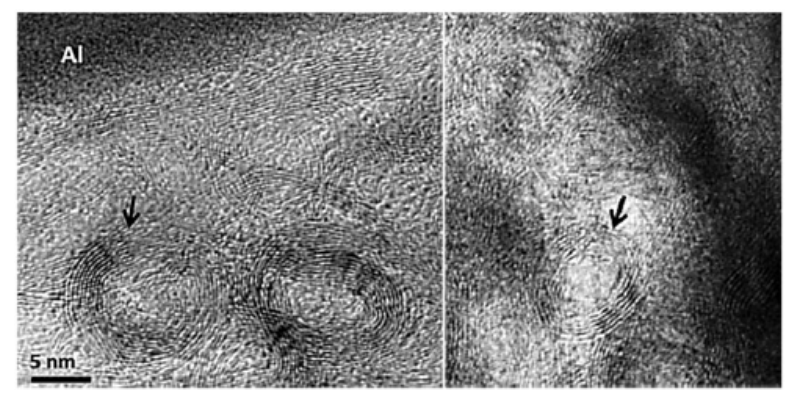

Figure 5. TEM images of Al/MWCNTs $0.5 \mathrm{wt} . \%$ after oxidation.

Table 1. Relative density and micro-hardness for pure aluminum and composites consolidated by SPS.

\begin{tabular}{|c|c|c|}
\hline Samples & $\begin{array}{c}\text { Relative } \\
\text { density }(\%)\end{array}$ & $\begin{array}{c}\text { Micro- } \\
\text { hardness (Hv) }\end{array}$ \\
\hline $\mathrm{Al}$ & 98.8 & $72.0 \pm 1.5$ \\
\hline $\mathrm{Al} / \mathrm{MWCNT-d}$ & 99.1 & $78.5 \pm 5.0$ \\
\hline $\mathrm{Al} / \mathrm{MWCNT}_{\mathrm{H} H N O}$ & 98.9 & $87.2 \pm 10.2$ \\
\hline $\mathrm{Al} / \mathrm{MWCNT}-\mathrm{SDS}$ & 98.9 & $90.0 \pm 5.8$ \\
\hline
\end{tabular}

\section{Density and Vickers micro-hardness}

As shown in Table 1, composites consolidated by Spark Plasma Sintering exhibit high density values whatever the powder preparation. It can also be seen that the microhardness increases of $\sim 25 \%$ compared to pure aluminum. Moreover, it's really interesting to note that the microhardness increases after each powder preparation step, indicating the CNTs dispersion improvement.

\section{CONCLUSION}

To succeed to uniformly disperse the MWCNTs within the aluminum matrix, several chemical treatments are necessary. After this process, the composite presents a good mechanical behavior as seen with the microhardness. 


\section{References}

[1] S. Iijima, "Helical microtubules of graphitic carbon". Nature, N0354, 1991, 56-58.

[2] I. Sridhar, K.R. Narayanan, "Processing and characterization of MWCNT reinforced aluminum matrix composites". Journal of Materials Science, No.44, 2009 1750-1756.

[3] J. Rausch, R.C. Zhuang, E. Mäder, "Surfactant assisted dispersion of functionnalized multi-walled carbon nanotubes in aqueous media". Composites: Part A, No.41, 2010, 1038-1046. 